\title{
Analysis of Satisfaction in the Use of Technological Simulation Tools in the Learning of the Automatic Process Control Course
}

\author{
https://doi.org/10.3991/ijep.v11i6.24911 \\ Omar Chamorro-Atalaya ${ }^{1(\varpi)}$, Guillermo Morales-Romero ${ }^{2}$, Adrián Quispe-Andía ${ }^{2}$, \\ Nicéforo Trinidad-Loli ${ }^{2}$, César León-Velarde ${ }^{3}$, Pedro Lezama-Gonzales ${ }^{4}$, \\ Joe Mendoza-Daza ${ }^{4}$ \\ ${ }^{1}$ National Technological University of Lima Sur, Lima, Peru \\ ${ }^{2}$ Universidad Nacional de Educación Enrique Guzmán y Valle, Lima, Perú \\ ${ }^{3}$ Universidad Tecnológica del Perú, Lima, Perú \\ ${ }^{4}$ Universidad Nacional Federico Villarreal, Lima, Perú \\ ochamorroduntels.edu.pe
}

\begin{abstract}
The objective of this article is to describe the satisfaction of students with the use of technological simulation tools in learning in the automatic process control course, as part of the pedagogical update in the context of distance education. The Academic Satisfaction Scale (ESA) was used as a measurement instrument, the reliability of the data was performed through Cronbach's alpha, giving a consistency value of 0.949 . When developing the research, it was determined that $56.8 \%$ of the students are satisfied with the academic experience of their learning using technological simulation tools in the virtual environment. On the other hand, $11.4 \%$ of students indicated that the content transmitted in this course does not excite them and they do not feel comfortable, these results will allow generating feedback to the teacher in their pedagogical techniques and teaching methods. Likewise, by means of $\mathrm{R}$ squared, it can be indicated that satisfaction towards the use of technological simulation tools in the course of automatic process control influences $63.7 \%$ in the evaluation of general satisfaction with the academic experience in the Virtual environment.
\end{abstract}

Keywords—-satisfaction, students, technological simulation tools, learning

\section{$1 \quad$ Introduction}

The development and innovation of new technological tools based on virtual platforms has opened up new spaces in the field of university teaching-learning $[1,2]$. However, it should be clear that, although educational technology is an important element to improve learning processes, it does not depend solely on its use, but on adequate curricular integration $[3,4]$. In this regard in $[5,6]$, the authors point out that in the university environment the teaching methodology is built on the basis of the achievement of the development of competences of the different subjects of the study 
plan, permanently linking the theoretical and experimental aspects through real tests and simulators.

Simulation is a technique that mimics a real experience that is commonly related to aspects that evokes or replicates the real world [7, 8]. In this regard, in [9], it is pointed out that simulation is a necessary technique in the educational environment. Also in [10] it is pointed out that simulation is an appropriate method for various engineering careers, where prior to experimental development, the student must be subjected to the analysis of results. Simulator-based learning sessions are considered successful, because they integrate science and technology, and guarantee learning experiences for students $[11,12]$.

Given this, it is important to contextualize the application of these technological simulation tools as part of the teaching-learning process. In the current health emergency scenario, where class sessions in many universities in Latin American countries are fully virtual, it is necessary to evaluate satisfaction with the use of tools from the university students' perspective [13-14]. In this regard, in [15,16] satisfaction is defined as a cognitive component of well-being, linked to the assessment of students when comparing their aspirations with their achievements.

Given what has been described, it is necessary to indicate that this research is carried out based on the level of dissatisfaction reflected in the low performance of the students, related to their practical skills, because, in this virtual context, the laboratory guides are not being developed or practical guides with equipment or automatic control devices, but they are developed with simulation software, in this sense it seeks to explore the improvement of satisfaction with the virtual teaching-learning modality.

In this sense, the present article aims to describe the results of the evaluation of the satisfaction of mechanical and electrical engineering university students, in the use of technological simulation tools, as part of the virtual learning of the automatic process control course. For which, initially the indicators that make up the only variable under study (satisfaction in the use of technological simulation tools) will be analyzed, to determine the relationship and influence that exists between them, through the curvilinear estimation analysis.

\section{Investigation methodology}

\subsection{Research level}

The research design is non-experimental, cross-sectional, because the data was collected simultaneously over a period of time on all the students that make up the study population. In this research, the results of student satisfaction will be analyzed, considering the context of the health emergency, in which the learning sessions take place totally virtual.

The research level is descriptive, since the results will be analyzed based on the frequency distribution of the satisfaction levels considered in the research instrument, determining the indicators that present the highest degree of satisfaction. Then the degree of association or influence will be determined through the coefficient of de- 
termination $\mathrm{R}^{2}$, using the SPSS, this analysis is carried out in order to know which of the indicators presents the greatest influence with the general indicator that indicates student satisfaction with academic experience in the virtual environment (I7).

\subsection{Population and sample}

The population is made up of 44 students, who took the required subject of control of automatic processes, of the Mechanical and Electrical Engineering career at the National Technological University of Lima Sur. In relation to the sample under study, it was made up of the entire population (44 students), due to the fact that the instrument could be applied to the entire population.

Although the population of this study is represented by 44 students, it should be noted that the survey was applied to all students at the public university in Peru, in a general and compulsory way, however, from the perspective of the university that seeks the Feedback from each teacher and the subject they teach, the teacher is provided with the results for their respective analysis, with the purpose of generating feedback on their pedagogical techniques and teaching methods.

For this reason, the population is simply reduced to students enrolled in each teacher's own subject, therefore, the sample in this case is equal to the population.

Given what has been described, it can be pointed out that the limitation of the study is based on the fact that the teacher performs the analysis only of the subject he is in charge of, this with the purpose of focusing strictly on their own and specific teaching techniques and methods in the development of your subject.

\subsection{Data collection technique and instrument}

The instrument used is a survey, the same one that is based on the academic satisfaction scale (AES), whose content validation is referenced in [16], however, some terms were modified in order to adapt them to the current context, where The teaching-learning process is developed through virtual platforms, this due to the social distancing in which Peru finds itself due to the declaration of the state of emergency by covid- 19 .

The survey is made up of seven questions that make up a single factor that measures the well-being and satisfaction of the students, and it was also applied in a non-face-to-face way through the university's virtual platform, in which the student enters through their user. and password, privately and confidentially.

The survey is mandatory, because there are rules and regulations, which dictate that the student must answer the surveys carried out, as part of a process of continuous improvement in each subject of the curricular plan. It is necessary to indicate that the time in which the survey corresponding to the last week of classes of each subject is carried out, in the academic registry.

Likewise, the reliability of the data was validated through Cronbach's alpha, the result of which is 0.949 . 


\section{Results and discussion}

\subsection{Description of learning based on the use of simulation software}

The subject of control of automatic processes, develops the thematic contents linked to four units, these being: Modeling of control systems, Time response of the controlled variable, PID controllers and Automatic control strategies. The pedagogical aspects imply the use of an active and student-centered methodology, the same one that involves the development of practical guides in synchronous and asynchronous learning sessions, in which the Matlab simulation software is used, with the following environments: command window, script, simulink and PID Autotuning, with these environments the course topics can be fully covered. It should be noted that the student teacher interaction takes place through Google Meet, and the virtual platform developed by the university. Figure 1 shows the interaction scheme of the elements that are part of Matlab's technological simulation tools, in the progressive acquisition of competencies and capacities of the subject.

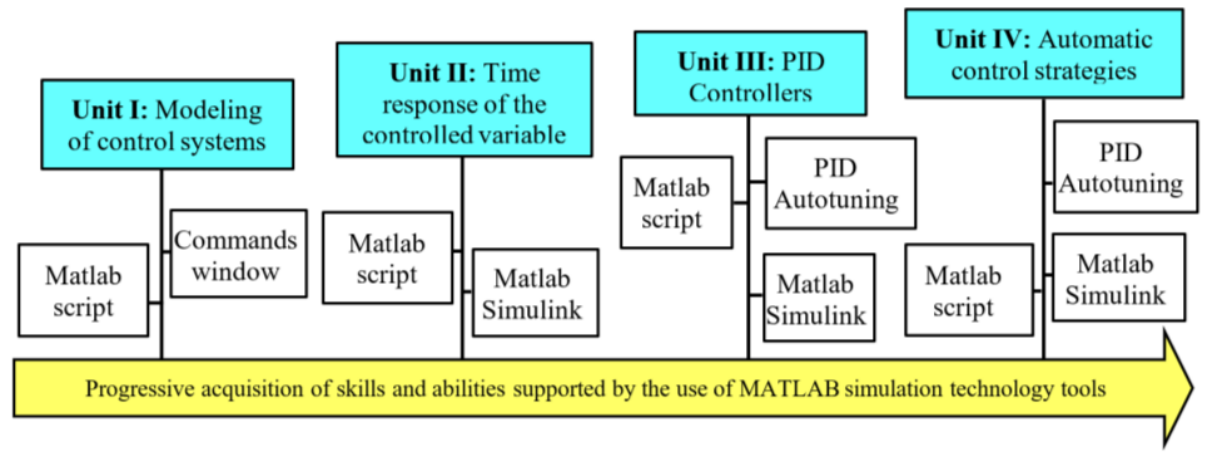

Fig. 1. Internment of thematic content and its progressive link with Matlab's technological simulation tools

\subsection{Results}

According to figure 2 of the 44 students surveyed, 34.1\% indicated that they fully agreed, with I1: "I feel comfortable in the virtual environment generated by the teacher", $15.9 \%$ were moderately in agreement and $11.4 \%$ were totally in agreement. in disagreement.

Regarding indicator I2: "I enjoy my virtual classes most of the time", 40.9\% indicated that they strongly agreed, $22.7 \%$ moderately agreed and $13.6 \%$ did not agree or disagree.

Regarding indicator I3: "I enjoy when they stimulate me intellectually in this subject", $47.7 \%$ indicated that they strongly agreed, $34.1 \%$ were moderately in agreement and $9.1 \%$ were moderately in disagreement. 
Regarding indicator I4: "I am enthusiastic about the contents transmitted in this subject", $54.5 \%$ indicated that they strongly agreed and $11.4 \%$ totally disagreed.

Regarding indicator I5: "I like what I have learned in this subject", 56.8\% indicated that they strongly agreed and $29.5 \%$ were moderately in agreement.

Regarding indicator I6: "I am satisfied with the subject developed in the virtual environment", $34.1 \%$ indicated that they strongly agreed and $25 \%$ were moderately in agreement.

Finally, regarding indicator I7: "In general I am satisfied with my academic experience in the virtual environment", $56.8 \%$ were in total agreement, $18.2 \%$ were moderately in agreement, $11.4 \%$ were neither in agreement nor in disagreement, $2.3 \%$ moderately disagreed and $11.3 \%$ totally disagreed.

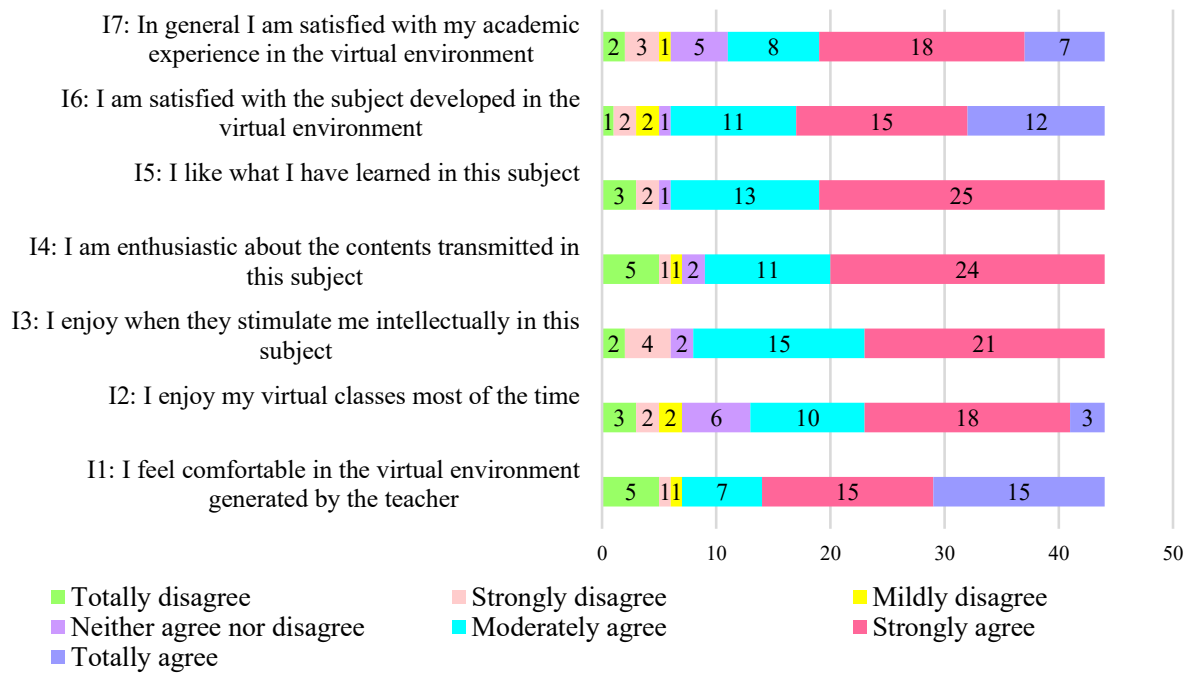

Fig. 2. Satisfaction with the use of technological simulation tools

Continuing with the development of the results and taking into consideration I7: "In general I am satisfied with my academic experience in the virtual environment", as the dependent factor, we will analyze the statistical behavior of the independent indicators (I1-I6), on I7. This curvilinear estimation test will indicate the degree of relationship and influence between the indicators. The results are shown in Table 1.

According to the ANOVA statistic indicated in table 1, the significance value for all the indicators is equal to 0.000 , which supports the correlation of the analyzed indicators, in turn the multiple correlation coefficient $\mathrm{R}$ or Pearson's coefficient, is 0.826 , this means that the degree or level of the relationship is very high. Likewise, by means of the R squared, it can be pointed out that indicator I6 is the one with the greatest influence with indicator (I7), in other words, it can be indicated that satisfaction towards the use of technological simulation tools in the automatic process control course (I6), it influences $63.7 \%$ in the evaluation of general satisfaction with the academic experience in the virtual environment (I7). 
Table 1. Estimation of the independent indicators on the dependent indicator

\begin{tabular}{|c|c|c|c|}
\hline \multirow{3}{*}{$\mathbf{R}$} & ANOVA & \multicolumn{2}{|c|}{ Parameter estimates } \\
\cline { 2 - 4 } & Significance & & R square \\
\hline \multirow{3}{*}{0.826} & \multirow{3}{*}{0.000} & Indicator 1 & 0.407 \\
\cline { 3 - 4 } & & Indicator 2 & 0.299 \\
\cline { 3 - 4 } & & Indicator 3 & 0.366 \\
\cline { 3 - 4 } & & Indicator 4 & 0.341 \\
\cline { 3 - 4 } & & Indicator 5 & 0.532 \\
\cline { 3 - 4 } & & Indicator 6 & 0.637 \\
\hline
\end{tabular}

\subsection{Discussion of results}

The results reveal that, in general, $56.8 \%$ of the students are satisfied with the academic experience in the virtual environment. Within these results, indicators I4 and I5 are integrated, as those that present the highest degree of satisfaction, with $56.8 \%$ of the students very much in agreement with what they have learned through the use of Matlab simulation technological tools in the subject. of the automatic process control course and $54.5 \%$ indicate that the technological tools used in the course content excite them. As noted in [14], student satisfaction with the teacher goes hand in hand with the integration of technological tools and resources in teaching.

As indicated in [8], the implementation of dynamic simulations through Matlab within the calculus teaching-learning process, in the first instance turned out to be quite effective, improving student performance by $18.51 \%$. The research of [3] supports what was obtained, because the results assert that the use of the Java simulator affects the learning of equivalent fractions, this can be observed in the significant difference between the statistical data of the control and experimental groups, as a result of the incidence in the use of Phet simulators in the development of the didactic unit between both groups, thereby generating a strong satisfaction in the students of the mathematics course [3]. As indicated in [18], there is a very strong relationship between learning and the actions of teachers, finding satisfaction with what was learned through didactic strategies at $\mathrm{R}^{2}=0.710$.

As highlighted in [10], the use of technological tools in education is no longer an option but a necessity. For this reason, it is important that teachers and students are integrated into the digital environment, thus generating a pedagogical reconfiguration on the part of teachers. As [11] points out, $59 \%$ of students prefer virtual tools to conventional classes, in addition the use of Information and Communication Technology (ICT) offers better performance than only the classical theoretical explanation of the teacher, in addition $62.5 \%$ affirmed that the ICT used were beneficial for classes.

\section{Conclusions}

With this work it has been possible to know the results of the evaluation of the satisfaction of university students of mechanical and electrical engineering, in the use of 
technological simulation tools, as part of the virtual learning of the automatic process control course. It can be concluded that the data and results obtained are reliable thanks to the application of Cronbach's alpha, which gave a consistency value of 0.949 , which guarantees the handling and processing of the data.

The use of dynamic simulation technological tools implemented in Matlab as part of the teaching-learning process of an automatic process control course, allow easy manipulation, making the student interested in its use, it is reflected in the satisfaction of the academic experience in the virtual environment. Since information and communication technologies (ICT) favor the teaching-learning process, allowing interaction between teachers and students. It can be seen that satisfaction when applying simulation for didactic objectives is related to the stimulus generated in student learning, because by enhancing their abilities and skills, it autonomously generates the development of their own experimental and conceptual knowledge, since the technological tools allow to place the student in situations that are related to the real world.

The mechanical and electrical engineering students mostly hold satisfactory opinions with the realization of the learning sessions with the help of the simulators, resulting in a very useful complementary tool for the teacher who teaches this subject, allowing them to deepen its contents. As noted, in virtual education the problem is not the technological tool used, but the use we make of it, therefore, the idea of choosing or preferring collaborative and interactive tools that generate satisfaction in students arises.

\section{$5 \quad$ Acknowledgment}

Thanks to the National Technological University of Lima Sur.

The metadata used in this article can be found at the following link: https://zenodo.org/record/5532898

\section{References}

[1] Arevalo, V., Vicente, J., Garcia-Morales I., Rivas-Blanco, I. (2020). Tutorials minivideos to support the learning of basic concepts for an automatic control foundation course. IberoAmerican Journal of Industrial Automation and Informatics, 17: 107-115, https://doi.org/ 10.4995/riai.2020.12156

[2] Mennickent, S., Granfeltdt, G., Zapata, D. Muñoz, S. (2019). Evaluation of the satisfaction of the use of a multiproject set to support the teaching-learning process for university students. Education and Health Science Journal, 17: 26-30.

[3] Díaz Pinzón, J. (2018). Learning mathematics with the use of simulation. SophiaEducation Journal, 14: 22-30.

[4] Li, C. (2021). Teaching Mechatronics to Non-traditional Mechanical Engineering Student -An adaptive Approach. International Journal of Engineering Pedagogy, 11: 4-20, https://doi.org/10.3991/ijep.v11i3.15833

[5] Ayón-Parrales, E., Víctores-Pérez, M. (2020). The simulation: Support strategy in the teaching of natural sciences in basic and high school, Portoviejo, Ecuador. Dominio in the Ciencias Journal, 6: 4-22. 
[6] Sousa, M, Fontao, E. (2020). Exploring learning in a Portuguese Engineering School: Are they different in different Courses. International Journal of Engineering Pedagogy, 10: 7894, https://doi.org/10.3991/ijep.v10i6.15237

[7] Fewella, L., Khoideir, L., Swidan, A. (2021). Impact of Integrated e-learning: Traditional Aprproach to teaching Engineering Perspective Courses. International Journal of Engineering Pedagogy, 11: 82-101, https://doi.org/10.3991/ijep. v11i2.17777

[8] Lema Carrera, M. (2018). Use of dynamic simulations in MatlaB as part of the teachinglearning processes of the derivative, integral and calculation of volumes. Scientific and Technological Journal, 5: 36-41.

[9] Bautista, I., Carrera, G., León, E., Laverde, D. (2020). Evaluation of student satisfaction about virtual classes. Minerva Journal of Scientific Research, 1: 5-12,

[10] Almetov N., Zhorabekova, A., Sgadullayev, I., Abilhairova, Z., Tulenova, K. (2020). Engineering Education: Problems of modernization in the context of a competence Aproach. International Journal of Engineering Pedagogy, 10: 7-20, https://doi.org/10.3991/ijep . $\mathrm{v} 10 \mathrm{i} 6.14043$

[11] Lopéz Guerrero, M., Lopez Guerrero, G., Rojano Ramos, S. (2018). Use of a simulator to facilitate the learning of the chemical reactions of the reactions: Case study of the University of Malaga. Chemistry Education Journal, 29: 79-98, http://dx.doi.org/10.22201/fq. $\underline{18708404 \mathrm{e} .2018 .3 .63728}$

[12] Molina-Hernandez, C., Gonzalez-Hernandez, W., Cruz Lemus, G. (2019). Didactic strategy to develop the ability to model dynamic processes of automatic control. Pedagogic Reference Journal, 8: 1-12.

[13] Jacques, S., Ouahabi, A., Lequeu, T. (2020). Remote Knowledge Acquisition and Assessment during the Covid-19 Pandemic, International Journal of Engineering Pedagogy, 10: 120-138, https://doi.org/10.3991/ijep.v10i6.16205

[14] Mateo, S., M., Jorge, S., David, V., Rita, V. (2020). Satisfaction evaluation of students on the use of Microsoft Teams software. Minerva Journal of Scientific Research, 1: 13-18.

[15] Muhammad, N., Srinivasan, S. (2021). Online Education during a pandemic - Adaptation and Impact on Student Learning. International Journal of Engineering Pedagogy, 11: 7183, https://doi.org/10.3991/ijep.v11i3.20449

[16] Vergara-Morales, J., Del Valle, M., Díaz, A., Pérez, M. (2018). Adaptation of the Academic Satisfaction Scale in Chilean University students. Educational Psychology Journal, 24: 99-106, https://doi.org/10.1037/t72992-000

[17] Torres Samuel, M., Vasquez Stanescu, C. (2015). Service quality evaluation models: characterization and analysis. Compendium Journal, 18: 57-76.

[18] Wolomasi, A., Asaloei, S., Redan, B. (2019). Job satisfaction and performance of elementary school teachers. International Journal of Evaluation and Research in Education, 8: 575-580, https://doi.org/10.11591/ijere.v8i4.20264

\section{$7 \quad$ Authors}

Omar Chamorro-Atalaya is with National Technological University of Lima Sur, Lima, Peru

Guillermo Morales-Romero, is with Universidad Nacional de Educación Enrique Guzmán y Valle, Lima, Perú

Adrián Quispe-Andía is with Universidad Nacional de Educación Enrique Guzmán y Valle, Lima, Perú. 
Nicéforo Trinidad-Loli is with Universidad Nacional de Educación Enrique Guzmán y Valle, Lima, Perú.

César León-Velarde is with Universidad Tecnológica del Perú, Lima, Perú.

Pedro Lezama-Gonzales is with Universidad Nacional Federico Villarreal, Lima, Perú.

Joe Mendoza-Daza is with Universidad Nacional Federico Villarreal, Lima, Perú.

Article submitted 2021-06-18. Resubmitted 2021-10-05. Final acceptance 2021-10-05. Final version published as submitted by the authors. 